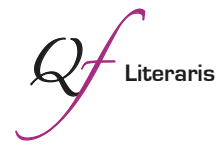

\title{
El testimonio recurrente de la experiencia concentracionaria de Jorge Semprún: dar voz al silencio y a la palabra
}

\author{
Beatriz Coca Méndez \\ Universidad de Valladolid \\ bcocam@ffr.uva.es
}

Resumen: La prosa sempruniana se caracteriza por la circularidad y la reiteración de ciertos episodios vividos, que ilustran pasajes de su narrativa -autobiográfica y de ficción. La iteración, más que recurso estilístico, parece dar consistencia a una inquietud de primer orden: dar consistencia al recuerdo de una experiencia límite y, por ello, perseguir sin descanso su vitalidad para que sea contraofensiva al olvido. El paso por Buchenwald es una vivencia capital para el escritor-testigo, ya que lo inefable de dicha experiencia requiere una organización estética que dé cartas de naturaleza a la sustancia que la nutre. La estructura reticular se torna una sutil tela de araña que enlaza los diferentes episodios, con la esperanza de dar voz a los acallados y a los que sobrevivieron.

Palabras clave: prosa concentracionaria; Buchenwald; memoria; autobiografía; Jorge Semprún.

The recurrent testimony of Jorge Semprún's concentrationary experience: To give voice to silence and word

\begin{abstract}
Semprún's prose is characterized by the circularity and repetition of certain experienced episodes that illustrate passages of his fiction and autobiographic narrative. The iteration, rather than a stylistic device, seems to embody a fundamental concern: give consistency to the memory of an extreme experience and, therefore, pursue its vitality not to be forgotten. The stay in Buchenwald is a unique experience for the writer-witness, as the unspeakable of this experience requires an aesthetic organization to give nature letters to the substance that nourishes it. The lattice structure turns into a spider web that links the different episodes of the story, hoping to give voice to the silenced and to those who survived.
\end{abstract}

Keywords: concentracionary prose; Buchenwald; memory; autobiography; Jorge Semprún.

\ Coca Méndez, Beatriz. 2016. "El testimonio recurrente de la experiencia concentracionaria de Jorge Semprún: dar voz al silencio y a la palabra". Quaderns de Filologia: Estudis Literaris XXI: 39-52. doi: 10.7203/qdfed.21.9333 

Esta reflexión se centra en el testimonio literario de Jorge Semprún, cuya obra -autobiográfica y de ficción- concede un espacio privilegiado a una experiencia tan imponente como es la travesía de la deportación. En consonancia con la impronta de dicha vivencia, Semprún no dejó de repetir "en el centro de todo está Buchenwald", no sólo como espacio imaginario sino como universo de fraternidad y de compromiso ético. Estos rasgos son constantes en su obra, por las huellas indelebles que dicha experiencia hubo de imprimir en lo más hondo de su ser y se inscriben en los relatos de su llamada prosa concentracionaria, a saber: El largo viaje (1963), Aquel domingo (1980), La escritura o la vida (1994) y Viviré con su nombre, morirá con el mio (2001)․ La recurrencia o, mejor dicho, la reescritura de dicha experiencia puede leerse a la luz que arroja cada novela, de forma que en su conjunto constituiría el viaje al fondo de la noche y el regreso de la brumosa irrealidad concentracionaria.

Como tantas veces se ha señalado, Jorge Semprún reúne la doble condición de víctima y testigo, lo que nos inspira designarlo narradortestigo al desdoblarse en narrador y protagonista del relato. Además, este autor se integra en el grupo heterogéneo de los testigos del mundo de la deportación, cuyo ahínco por dejar testimonio de ese universo totalitario los convierte en militantes de una misma causa: dar aliento a la memoria frente al olvido, aun cuando no todos los supervivientes se pusieron manos a la obra a un mismo tiempo; prontitud o tardanza, que estará motivada por razones vitales $\mathrm{y}$, sobre todo, por impulsos tan íntimos como personales.

En el caso que nos ocupa, Jorge Semprún tardará unos quince años en hacer su viaje a la escritura; escritura que le impedía vivir y le devolvía a la muerte -"sólo puedo vivir asumiendo esta muerte mediante la escritura, pero la escritura me prohíbe literalmente vivir” (1995: 180)-,

\footnotetext{
${ }^{1}$ Hemos indicado las fechas de su aparición en lengua francesa, dado que la traducción al español no siempre fue inmediata. En el ámbito idiomático, hay que reseñar que estos títulos en español adaptan las connotaciones simbólicas que tienen en francés, así Le grand voyage, sinónimo de la muerte, deviene El largo viaje incidiendo en las hondas consecuencias que tuvo dicha travesía. Le mort qu'il faut -el muerto que necesitamosse transforma en Viviré con su nombre, morirá con el mío como alusión al cambio de identidades que se efectuaban en la Arbeitsstatistik con el fin de preservar la vida de determinados camaradas; la ilustración que acompaña la portada del libro, Dachau (1945) de Zoran Music, representa en su grafismo el título en español, así como las condiciones en las que se compartía el catre.
} 
hasta el punto de que el primer esbozo de La escritura o la vida fechado en 1987 se tituló provisionalmente La escritura o la muerte (1995: 249), disociación altamente elocuente de la simbiosis que las unía. Por otra parte, no deja de ser sorprendente que la obra de Semprún esté escrita en francés ${ }^{2}$ casi en su totalidad; sorprendente porque el autor dirá que redescubre la lengua de su infancia cuando ingresa en Buchenwald, mientras que la plasmación literaria de dicha vivencia a partir de 1961 sería en francés, la lengua materna del exilio.

\section{Una vida novelesca y azarosa}

Aunque español de origen, Jorge Semprún es un escritor de expresión francesa, puesto que su vida y obra se ubican a ambos lados de los Pirineos: nace en Madrid en diciembre de 1923 y fallece en París en junio de 2011. Cronología que marca los extremos de una intensa andadura vital, íntimamente relacionada con ciertos acontecimientos capitales del siglo XX: la Guerra Civil española y la terrible experiencia de la deportación en Buchenwald.

Como tantas veces se ha indicado, "la verdadera aventura de Jorge Semprún empieza en el mes de julio de 1936", porque las amenazas que se cernían sobre la República atrapan a la familia Semprún como a tantos otros. No obstante, aquélla se instala en Lekeitio, donde veraneaba desde 1933 y, siguiendo la costumbre, cierra la casa madrileña de la calle Alfonso XI; la guerra va a alterar el acontecer de las gentes y, en su caso, la pérdida irremediable del hogar familiar y de la ciudad de la infancia. Con apenas 14 años, Semprún es consciente del sentimiento de pérdida y desarraigo, como dejará constancia en su novela Adiós, luz de veranos... En septiembre de 1936, a bordo del pesquero Galerna, se inicia la errancia de la familia: el sur de Francia, Ginebra con la dispersión familiar, La Haya y finalmente París, adonde es enviado el joven Semprún para proseguir el bachillerato en el liceo Henri-IV.

En los años siguientes, y ante el rumbo de los acontecimientos ${ }^{3}$, Semprún pasa a la acción al incorporarse a la Resistencia y cuando

\footnotetext{
${ }^{2}$ En la producción sempruniana, la excepción la marcan Autobiografía de Federico Sánchez (1977) y Veinte años y un día (2003), escritas en español.

${ }^{3}$ La presumible brevedad de la drôle de guerre contradice tanto su duración como las consecuencias de ésta.
} 
ingresa en el Partido Comunista de España en 1942. Al año siguiente y con veinte años, es detenido por la Gestapo y deportado a Buchenwald, donde, entre el 29 de enero de 1944 y el 11 de abril de 1945, transcurren 16 meses decisivos en la vida de Semprún. Como este rojo español -Rotspanier- habla alemán podrá salvar su vida. Tras el preceptivo proceso de ingreso en el campo -rasurado, cuarentena...-, Semprún es designado a la Arbeitsstatistik, donde se efectúa la distribución de mano de obra, así como el censo de fallecidos, enfermos y recién incorporados al campo, tarea que le permitirá tomar conciencia de las consecuencias cruciales que derivan de una identidad prestada. A su ingreso en el campo -como ilustra el episodio 10 "Retorno a Weimar" de La escritura o la vida- el trueque del estatus de estudiante por el de Stukkateur, sinónimo de productividad, es crucial para el deportado 44.904, tanto como saber alemán: "Estar bien de salud, tener curiosidad y saber alemán: la suerte se encargaría del resto" (Semprún,1995: 320).

En 1945 y de regreso en París, dirige la acción clandestina del PCE. Dedicado exclusivamente al activismo político, Semprún vive clandestinamente en Madrid (1953-1962) atrincherado en pseudónimos o nombres de guerra, entre los cuales será Federico Sánchez el más conocido. Sin embargo, este exilio interior toca a su fin en 1964, cuando se produce la ruptura con el comunismo y es expulsado del partido. Esta quiebra ideológica no será, sin embargo, menoscabo a su compromiso político y a su querencia por la acción, como dan cuenta su designación como ministro de Cultura (1988-91) en el Gobierno de Felipe González y sus innumerables intervenciones públicas sobre asuntos candentes del momento.

\section{La amnesia voluntaria}

Este esbozo biográfico permite, no obstante, destacar dos fechas señeras en la andadura de Semprún, y que determinan un antes y un después categóricos: la primera vida sellada el 11 de abril de 1945 y la segunda iniciada en 1964. Ahora bien, los dos extremos de este segmento vital están puntuados tanto por las ansias de consumir el presente juvenil como por exorcizar los fantasmas del pasado: zozobra que se salda con la llamada decisión de Ascona. Ese viaje a Suiza en el verano de 1945 inaugura el retorno a la vida lacrando el pasado en el silencio del olvido: "En Ascona, pues, bajo un sol de invierno, decidí optar por el silencio 
rumoroso de la vida en contra del lenguaje asesino de la escritura. [...] Me convertí en otro para poder seguir siendo yo mismo" (1995: 244).

Durante unos quince años, Semprún vivirá en el anonimato y al amor del olvido, gestado en esa cura de silencio y en la amnesia voluntaria; voluntaria para hacer frente a las amenazas borrascosas de la nieve o al torbellino de sus copos, signo de la desasosegante presencia de la muerte y augurio de la memoria que la acompañaba ${ }^{4}$. El peso del recuerdo se torna el duelo de la memoria, por la necesidad imperiosa de domar los fantasmas del pasado y de dotarse, en suma, de unos signos de identidad nuevos:

Mi proyecto resultaba irrealizable, por lo menos en lo inmediato y en su totalidad sistemática. El recuerdo de Buchenwald era demasiado denso, demasiado despiadado, para que yo pudiera alcanzar de entrada una forma literaria tan depurada, tan abstracta. [...] Sólo un grito que proviniera del fondo de las entrañas, sólo un silencio de muerte podría haber podido expresar el sufrimiento (1995: 175).

El compromiso político y, sobre todo, las expectativas que envuelven la acción clandestina de Semprún en los años 50, no sólo inciden en el oxímoron antes señalado - el silencio rumoroso de la vida- sino en el revestimiento del impulso vital y, por lo mismo, en expresión implícita de las esperanzas que animan la acción política. Esta nueva vida, trasunto de un viaje iniciático, semeja "una aventura arriesgada, una profesión y en un escenario inédito, el del propio país por descubrir" (Nieto, 2014: 169).

Los albores de los años 60 serán decisivos en la vida de Semprún, no sólo porque 1961 sella su nacimiento como escritor, sino porque 1964 inaugura el tiempo del revisionismo ideológico -“el tiempo del silencio y del olvido había quedado atrás. El tiempo de la sordera para conmigo mismo también: para con la parte más oscura pero más verdadera de mí mismo" (1995: 255)-; el olvido voluntario antes restañado por la acción política deviene un trayecto inverso: la acción y el compromiso

\footnotetext{
${ }^{4}$ Los episodios que caracterizarán la biografía de Jorge Semprún también serán legados o transferidos a sus personajes de ficción. El viaje a Suiza, incluida Ascona, así como el simbolismo de la nieve o del torbellino que la acompaña, augurio de la zozobra o de la ausencia del personaje, irrumpen igualmente en la vida de Manuel en El desvanecimiento o de Juan Larrea en La montaña blanca.
} 
personal se proyectarán en la vigencia y vivencia de un testimonio que ya no se circunscriben únicamente a las secuelas del Holocausto. En el epicentro de Weimar, el universo totalitario del nazismo, lejos de eclipsar la gravedad del estalinismo, derrumbará sus alambradas para dar cobijo al mundo opresivo del gulag. La fractura ideológica de Semprún tiene que ver, sin duda, con el alcance reflexivo y crítico que proyecta sobre el universo de antaño, tan disímil y tan semejante, así como con las amenazas que pueden cernirse de nuevo en el futuro:

El único lugar en el mundo que los dos totalitarismos del siglo XX, el nazismo y el bolchevismo, (el integrismo islámico llevará a cabo los estragos más masivos si no lo contrarrestamos con una política de reforma y de justicia planetarias, en el siglo XXI), habrán marcado conjuntamente con su impronta (1995: 307).

En este sentido es significativo que El largo viaje concluya a las puertas de Buchenwald, mientras que en 1980 su obra Aquel domingo también se proyecta sobre los campos estalinistas con el objeto de dar cuenta del carácter tan diverso como semejante del universo concentracionario. La ampliación de la perspectiva deriva del revisionismo personal de Semprún, de manera que el relato de una tarde de domingo en Buchenwald se presta también al recuerdo de episodios señeros de la biografía del narrador-testigo: el exilio, la deportación, el viaje a Praga en abril de $1964 .$. En esta esfera declarativa, también son significativas las alusiones a aquellos compatriotas republicanos que pasaron por los campos de Argelès y del sur de Francia antes de formar parte de la geografía de la deportación. Sin embargo, el hecho común de unas duras condiciones de vida y del espacio de fraternidad que en ellos se constituyó da mayor realce a los estragos que se infringió a la dignidad humana, a través de la aniquilación o la perversión de la memoria. Como observa Joan-Carles Mèlich (2004: 86), la sumisión no será más que un eslabón en el triunfo del olvido, cuyo éxito sería la desaparición física y material de los testigos, particularidad que explica la omnipresencia y el simbolismo de la chimenea del campo: "la señal más específica de ese conjunto, la cuadrada y maciza chimenea del crematorio" (Semprún, 2011: 194).

El silencio será, pues, el lenitivo a la escritura. Ahora bien, como observa Sánchez-Zapatero (2010: 74-76), la tendencia al silencio estuvo alentada también por causas de tipo sociológico como fue cierta 
ignorancia, la cercanía del final de la deportación o el deseo de olvidar por parte de los coetáneos. En este sentido, es elocuente la mirada que se proyecta sobre una población vecina a Buchenwald ${ }^{5}$ antes y después de la deportación, para incidir en el manto de silencio que envolvía a los deportados:

Hemos venido a buscar la vida de antes, la vida de fuera. Pero con nosotros hemos traído la amenaza de lo desconocido, de una realidad hasta ayer criminal y punible. [...] El pueblo nos expulsa, expulsa el ruido de nuestras botas, nuestra presencia insultante para su tranquilidad, para su ignorante buena conciencia, expulsa nuestros trajes rayados, nuestros cráneos rasurados, nuestras miradas de los domingos que descubrían la vida de afuera en este pueblo (Semprún, 2011: 123-124).

En cambio, el silencio que, implícitamente, se imponía chocó con el deseo inmediato e imperioso de algunos supervivientes por dejar huella de su testimonio, como fue el caso de Primo Levi, que en 1947 escribe Si esto es un hombre; otros, por el contrario, serán menos raudos en el testimonio escrito. El discurrir del tiempo irá alentando el culto a la memoria, de manera que el hándicap inicial que sintieron los supervivientes ante la disfunción de ser escuchados por poco creíbles también irá ganando la confianza del lector. Se produce, en suma, un proceso semejante en el narrador y en el lector: la interiorización de dicha confesión facilita la disposición de escuchar y, por lo tanto, de compartir una memoria tan colectiva como personal.

Según observa Paul Ricoeur (2000: 580-582), el resurgir del recuerdo ha de pasar no sólo por su organización, sino por la consiguiente etapa de duelo y erupción de los fantasmas reprimidos. El testimonio escrito atiende, pues, a la selección y organización del recuerdo y, en

\footnotetext{
${ }^{5}$ El complejo que se construye en torno a Buchenwald hasta finalizar la guerra modifica sustantivamente su concepción inicial. El número de prisioneros fue aumentado considerablemente a medida que se extendía la guerra y, por ello, también hubo de acoger a judíos. En sus inicios, los prisioneros se dedican a la ampliación de las instalaciones del campo y a la construcción de otras edificaciones destinadas a los jefes y tropas de las SS, incluidas "otras edificaciones para solaz de los verdugos nazis". Esta particularidad incide en la indiferencia o silencio deseado por parte de la población civil, y hace aún más elocuente dicha actitud: "Estas instalaciones recreativas eran accesibles a las poblaciones próximas al campo, que podían disfrutar de ellas en las apacibles tardes dominicales sin hacerse cuestión de la presencia de la masa extraña de deportados" (Nieto, 2014: 36-37).
} 
consecuencia, a la representación del pasado, fruto del concierto que se establecerá entre la memoria saturada y la memoria apaciguada, entre la memoria personal y la colectiva. Ahora bien, este proceso no es tan sencillo, por la propia especificidad de una experiencia marcada por la dificultad de materializar verbalmente lo indecible o lo innombrable (Didi-Huberman: 2006: 1025). En el caso de la prosa sempruniana, y una vez recobrado el poder de la escritura, el narrador-testigo pondrá su empeño tanto en la posibilidad de relatar como en el compromiso ético que lo inspira:

No porque la experiencia vivida sea indecible. Ha sido invivible, algo del todo diferente, como se comprende sin dificultad. Algo que no atañe a la forma de un relato posible, sino a su sustancia. No a su articulación, sino a su densidad (Semprún, 1995: 25).

Desde este punto de vista, el peso de ciertos episodios biográficos ${ }^{6}$ cobra tal importancia que son omnipresentes en sus relatos, aun cuando la intencionalidad que los inspira atiende forzosamente a la trama y a la sustancia de la obra.

\section{El deber de la escritura}

Como se ha indicado, Jorge Semprún tardará en blandir la pluma como arma de combate. Si bien el renacer a la escritura está mediatizado por el testimonio de Manuel Azaustre acerca de su experiencia en Mauthausen, cuando, inmovilizado en su domicilio de la calle Concepción Bahamonde en 1961, Jorge Semprún emprende la escritura de El Largo $v_{\text {viaje}}$. Esta novela es decisiva en la producción sempruniana, no sólo por su carácter inaugural o fundacional, sino porque en ella ya están

\footnotetext{
${ }^{6}$ En la obra de ficción de Semprún, ciertos personajes se ven tocados con algunos episodios del pasado concentracionario del autor, como queda reflejado en la novela Netchaiev ha vuelto.

${ }^{7}$ El carácter fundacional de esta obra deriva de un aspecto simbólico que el propio Semprún refiere en La escritura o la vida cuando recibe el premio Formentor. En el momento que le entregan la versión española, las páginas de ese ejemplar están en blanco, lo que puede interpretarse como el augurio de la reescritura característica de la poética sempruniana. En un sentido más pragmático, la ausencia de texto se debió a que la obra estaba censurada en España y no se publicaría hasta 1976, como observa Semilla-Durán (2005: 51).
} 
inscritos los rasgos de la poética sempruniana, así como el compromiso ético que la inspira:

Todo me parecía claro, a partir de ahora. Sabía cómo escribir el libro que había tenido que abandonar quince años antes. Mejor dicho: sabía que podía escribirlo, a partir de ahora. Pues siempre había sabido cómo escribirlo: me había faltado valor para hacerlo. Pero ya no tenía necesidad de ese valor (Semprún, 1995: 260).

Desde esta perspectiva, se puede argüir que la prosa concentracionaria de Semprún es obra de madurez, lo cual hace pensar en la solidez de sus convicciones escripturales, éticas y estéticas. Por otra parte, las imbricaciones que se establecen entre estas cuatro obras permiten esbozar la trayectoria que seguiría el tren carcelario para trazar un triángulo: El largo viaje concluye en las puertas del campo que, nuevamente, se abren en el transcurrir de Aquel Domingo y confluyen en el sempiterno bloque 40 de Viviré con su nombre, moriré con el suyo. En el epicentro de este imaginario triángulo se situaría La escritura o la vida, no sólo por recrear la ascesis que hubo de sufrir Semprún, sino porque retoma la imagen directriz de su primera novela: entrar/salir, antes/después...; esta obra escrita a los 71 años condensa la expresión de las inquietudes del superviviente: el compromiso ético respecto de sus camaradas, la veracidad y verosimilitud del relato, así como la recreación de la vivencia. Se puede decir que Jorge Semprún -así como en su novelística- va desgranando al lector las motivaciones de su escritura, sus inquietudes formales, y con sus reflexiones le hace partícipe de su universo personal.

El compromiso ético se debe esencialmente al deseo de contrarrestar la aniquilación de la memoria. Por un lado, se trata de la implacable desaparición de los testigos, presentada desde la óptica del interés científico: la producción de documentos, novelas o relatos (Semprún, 1995: 141-144), así como del compromiso de rendir memoria a tal acontecimiento. En la obra de Semprún el peso de la memoria se torna un eje narrativo y, por lo mismo, en tema vertebrador del relato:

Ya no habrá testigos, o, mejor dicho, ya no habrá más que "testigos verdaderos", es decir, muertos; pronto nadie podrá tocarles los huevos con fastidiosos recuerdos personales, Erlebnis, "vivencia" de una muerte de la que, más que supervivientes, hay aparecidos (2001: 209). 
En este sentido, la vitalidad del testimonio es un tema recurrente en la prosa sempruniana, no sólo por la inexorable desaparición de los testigos, sino también por el carácter que tendrá la continuidad de dicho recuerdo. Ahora bien, con la desaparición de los testigos también desaparece el peso del recuerdo y, con él, el sempiterno olor a carne quemada, germen de tantas reflexiones e imágenes literarias.

En el aspecto formal, se puede decir que Semprún no cultiva especialmente el relato realista o los estereotipos del testimonio lacrimoso, ya que el propio autor se impone las cortapisas morales de no quebrantar ni la veracidad ni la verosimilitud del relato:

Nada es verdad sino el humo del crematorio de Buchenwald, el olor a carne quemada, el hambre, las filas en formación bajo la nieve, los bastonazos, la muerte de Maurice Halbwachs y de Diego Morales, la fetidez fraternal de las letrinas del Campo Pequeño (Semprún, 1995: 254).

Tratándose de un universo marcado por unas condiciones de vida tan duras, es insoslayable que éstas aparezcan en fugaces alusiones a lo largo del relato; ahora bien, la intertextualidad que se teje entre las obras dota a esta impronta de una densidad que trasciende su laconismo, dado que los estragos infringidos no son más que la consecuencia del mal que anida en el ser humano, de ahí que la plasticidad de las imágenes persiga trascender el grafismo para incidir en la causa-efecto que lo inspiró: "El envite será la exploración del alma humana en el horror del Mal...¡Necesitamos un Dostoievski!” (Semprún, 1995: 144).

La plasmación realista de la vida concentracionaria no parece, pues, ser el numen del escritor, ante lo que puede adoptar un tono displicente -"nuestros ridículos recuerdos de hornos crematorios y de formaciones interminables bajo la nieve" (Semprún, 2011: 19). En esta línea creativa, se puede decir que los títulos de estas cuatro obras poco se hacen eco de la vivencia o universo que los inspiró, quizá porque el autor ya perseguía atrapar y realzar la polisemia de lo simbólico. Asimismo, aquellas verdades, por sabidas, no parecen ser de especial interés para el autor, aun cuando son innegables, como innegable es el homenaje que rinde a los supervivientes y a los que se fueron en humo, cuyas condiciones de vida no menguaron el espacio de fraternidad que entre ellos se creó curiosamente en las letrinas, a pesar de que el autor lamente la promiscuidad que en ellas se dio por la omnipresencia de la mirada 
del otro, signo de la privación de la ínfima privacidad que les quedaba. Ahora bien, el universo mental común y una geografía compartida son la forja de este lazo indeleble, es decir: signo de fraternidad y hermandad que se prolonga en un viaje de tan hondo calado:

Todo había terminado, íbamos a hacer este mismo viaje en sentido contrario, pero quizás este viaje nunca puede hacerse en sentido contrario, tal vez este viaje no se puede borrar jamás (2011: 25).

El propósito de relatar esta vivencia en el sentido de ida y vuelta pretende ser tan significativa como simbólica. Como se ha indicado, Jorge Semprún envuelve su relato con la densidad que las reflexiones inspiran lo presentado, tras su búsqueda en los meandros brumosos de la memoria (Wachowska, 2015: 219). A tal efecto, el relato sempruniano se construye sobre una red de asociaciones que lo fragmentan para perderse en los recuerdos más recónditos, de manera que la unidad del relato discontinuo reposa en la sutil red de correspondencias ya indicadas -antes/después, dentro/fuera, entrar/salir, salir/volver-, entre las cuales se van entreverando recuerdos, reflexiones y cavilaciones, que están inspiradas por un detalle, una fecha, una canción...

Ahora bien, el relato discontinuo, característico de la poética sempruniana, más que una licencia narrativa parece buscado por el relatortestigo con el fin de establecer un pacto de lectura con el lector, azuzándolo en el deambular zigzagueante del relato y con unos interrogantes que quizá carecen de una respuesta categórica, después de transitar por este universo personal y colectivo. En este sentido, los episodios que configuran la trama narrativa incluyen, evidentemente, las imágenes pertinentes y necesarias del universo concentracionario, como son el leitmotiv del tren carcelario, la nieve, el frío, el hambre, la formación y la omnipresente plaza de recuento.

Desde el punto de vista del simbolismo, el autor busca y recrea las connotaciones y la polisemia que envuelve a los términos. En el traslado del tren a Buchenwald el hacinamiento es presentado como magma de cuerpos, magma gangoso y ante la proximidad de la muerte son troncos de árboles podados. En este sentido, las connotaciones del término noche, aunando la soledad y la oscuridad, designa tanto la guerra como el estado de ánimo de las víctimas: la noche eterna, el frío de la noche, la noche de la locura. 
La presentación de las escenas es resultado de la observación y de la mirada o, más bien, del intercambio de miradas: el observado y el observador, como ilustra el episodio 1 de La escritura o la vida: "Están delante de mí, abriendo los ojos enormemente y yo me veo de golpe en esa mirada de espanto: en su pavor" (Semprún, 1995: 15). Observar y testimoniar parece el propósito del narrador-testigo, que recurre a la poética de la repetición y de la iteración para impregnar de intensidad la imagen que ofrece al lector, envolviéndolo en el efecto encantador de la repetición:

Era el último invierno de aquella guerra, el invierno más frío de esta guerra cuya suerte se decidió en medio del frío y de la nieve [...]. Los árboles estaban cubiertos de nieve, cubiertas de nieve las carreteras, y en el campo de cuarentena nos hundíamos en la nieve hasta la rodilla. Los judíos de Polonia llegaban apiñados en vagones de mercancías, cerca de doscientos por vagón, y habían viajado durante días y días sin comer ni beber, en el frío de este invierno que fue el más frío de aquella guerra. En la estación del campo, cuando se abrían las puertas correderas, nada se movía, la mayoría de los judíos había muerto de pie, muertos de frío (Semprún, 2011: 166-167).

La estética de la repetición quizá atiende a la consistencia y evanescencia del recuerdo, así como a los interrogantes que atenazan al narradortestigo: "me había despertado, otra vez -o todavía, o para siempre- en la realidad de Buchenwald: que jamás había salido de allí, a pesar de las apariencias, que jamás saldría de allí, a pesar de los simulacros y melindres de la existencia" (Semprún,1995: 169). Esta confesión de angustia, también generalizada entre los deportados (Vilanova, 2014: 129-130), no sólo es acicate para indagar en la memoria, sino también el proceso para dar consistencia verbal a lo vivido, a través del simbolismo de la palabra y de la iteración. El eco que perpetúa la sonoridad de términos clave a lo largo del relato deviene el hilo de Ariadna que configura la identidad del narrador y apacigua sus fantasmas. En este sentido, no es insustancial la simbiosis que se opera al final de La escritura o la vida entre dos tiempos distintos que concluyen en la geografía íntima y personal de Jorge Semprún; enero de 1943 se funde y confunde en marzo de 1992: 
De repente, yo tenía veinte años y caminaba muy deprisa entre los torbellinos de nieve, aquí mismo, pero muchos años antes. Aquel remoto domingo, cuando Kaminski me convocó a la reunión donde escuchamos al superviviente del Sonderkommando de Auschwitz. [...]

Ya no estaba soñando, había regresado a ese sueño que había sido mi vida, que será mi vida (Semprún, 1995: 327).

\section{Bibliografía}

Augstein, Franciska. 2010. Lealtad y traición. Jorge Semprún y su siglo. Barcelona: Tusquets.

Didi-Huberman, Georges. 2006/5. Ouvrir les camps, fermer les yeux. Annales. Histoire, Sciences Sociales, 2006/5, 61e année: 1011-1049. http:/www. cairn.info/revue-annales-2006-5-page-1011.htm

Mèlich, Joan-Carles. 2004. La lección de Auschwitz. Barcelona: Herder.

Mertens, Pierre. (janvier 2005). Ils ont nommé l'innommable. Magazine littéraire 438: 30-32.

Nieto, Felipe. 2014. La aventura comunista de Jorge Semprún: exilio, clandestinidad y ruptura. Barcelona: Tusquets.

Ricoeur, Paul. 2000. La mémoire, l'histoire, l'oubli. Paris: Seuil.

Sánchez-Zapatero, Javier. 2010. Escribir el horror. Literatura y campos de concentración. Barcelona: Montesinos.

Semprún, Jorge. 1995. La escritura o la vida. Barcelona: Tusquets.

Semprún, Jorge. 1999. Aquel domingo. Barcelona: Tusquets.

Semprún, Jorge. 2011. El largo viaje. Barcelona: Tusquets.

Semprún, Jorge. 2012. Viviré con su nombre, morirá con el mío. Barcelona: Fábula Tusquets.

Semilla-Durán, Maria-Angélica (2005). Le masque et le masqué. Jorge Semprún et les abîmes de la mémoire. Toulouse: Presses Universitaires du Mirail.

Vilanova, Mercedes. 2014. Mauthausen, después. Voces de españoles deportados. Madrid: Cátedra.

Wachowska, Judyta. 2015. El universo concentracionario en las novelas de Jorge Semprún: historia, memoria, escritura. En García Bascuñana, Juan F. (ed.) Jorge Semprún: memoria, historia, literatura. Mémoire, histoire, littérature. Bern: Peter Lang, 207-225. 